\title{
CARACTERIZAÇÃO FITOSSOCIOLÓGICA E FITOGEOGRÁFICA DE UM TRECHO DE FLORESTA CILIAR EM ALFREDO WAGNER, SC, COMO SUBSÍDIO PARA RESTAURAÇÃO ECOLÓGICA
}

\author{
PHYTOSOCIOLOGICAL AND PHYTOGEOGRAPHIC CHARACTERIZATION OF A RIPARIAN \\ FOREST SECTOR IN ALFREDO WAGNER, SANTA CATARINA STATE, AS SUBSIDY FOR \\ ECOLOGICAL RESTORATION
}

\author{
Ana Carolina da Silva ${ }^{1}$ Pedro Higuchi ${ }^{2}$ Marcelo Negrini ${ }^{3}$ Andriele Grudtner ${ }^{4}$ Diego Fernando Zech ${ }^{5}$
}

\section{RESUMO}

Os conhecimentos florístico e estrutural da comunidade arbórea são fundamentais para subsidiar estratégias de restauração florestal. Neste sentido, foi realizado um levantamento fitossociológico em um fragmento florestal situado nas margens de um tributário do Rio Caeté em Alfredo Wagner, SC, objetivando: i) conhecer a estrutura e a florística da vegetação arbórea dessa floresta; ii) classificar as espécies encontradas em grupos ecológicos e iii) comparar a florística da área estudada com outros estudos realizados em Floresta Ombrófila Mista (FOM), Floresta Ombrófila Densa (FOD) e área de transição entre FOM-FOD de Santa Catarina. Nesse fragmento foram alocadas 10 parcelas de $400 \mathrm{~m}^{2}$ onde todos os indivíduos arbóreos que apresentaram Circunferência a Altura do Peito (CAP, medido a $1,30 \mathrm{~m}$ do solo) igual ou superior a $15,7 \mathrm{~cm}$ foram medidos, marcados e identificados. As espécies foram classificadas nos grupos sucessionais: pioneira, clímax exigente de luz ou clímax tolerante à sombra. Para a comparação florística com outros remanescentes, foi utilizada a Análise de Correspondência Retificada (DCA). A estrutura do componente arbóreo foi descrita pela densidade, frequência, dominância e Valor de Importância (VI). Os resultados demonstram elevada riqueza florística (98 espécies). Foi possível constatar espécies típicas de FOM, como Araucaria angustifolia (Bert.) Kuntze, e espécies características de FOD, como Byrsonima ligustrifolia A.Juss., confirmando a característica do fragmento estudado de pertencer a uma área de tensão ecológica, padrão confirmado na comparação da similaridade florística. As espécies com maior VI foram Psychotria vellosiana Benth., Alsophila setosa Kaulf. e Guatteria australis A.St.-Hil. Estas e outras espécies de alto VI, por suas consideráveis representatividades na área, são importantes na restauração de florestas ciliares degradadas na região. Os plantios deverão ser planejados obedecendo-se ao grupo sucessional das espécies, plantando-se as espécies pioneiras e clímax exigentes de luz em um primeiro momento (e.g. Psychotria vellosiana), seguidas, quando houver o sombreamento da área, das espécies clímax tolerantes à sombra (e.g. Alsophila setosa e Guatteria australis).

Palavras-chave: Floresta Ombrófila Densa; Floresta Ombrófila Mista; florística; estrutura.

\begin{abstract}
The understanding of floristic and structure of tree communities is essential to subside the strategies of forest restoration. In this sense, a phyto-sociological survey was conducted in a forest fragment situated

1 Engenheira Florestal, Dr ${ }^{\mathrm{a}}$., Professora Adjunto do Departamento de Engenharia Florestal, Universidade do Estado de Santa Catarina. Av. Luiz de Camões, 2090, Bairro Conta Dinheiro, CEP 88520-000, Lages (SC), Brasil. carol_sil4@yahoo.com.br

2 Engenheiro Florestal, Dr., Professor Adjunto do Departamento de Engenharia Florestal, Universidade do Estado de Santa Catarina, Av. Luiz de Camões, 2090, Bairro Conta Dinheiro, CEP 88520-000, Lages (SC), Brasil. higuchip@gmail.com

3 Engenheiro Florestal, Departamento de Engenharia Florestal, Universidade do Estado de Santa Catarina, Av. Luiz de Camões, 2090, Bairro Conta Dinheiro, CEP 88520-000, Lages (SC), Brasil. engfmarcelonegrini@hotmail.com

4 Engenheira Florestal, Departamento de Engenharia Florestal, Universidade do Estado de Santa Catarina, Av. Luiz de Camões, 2090, Bairro Conta Dinheiro, CEP 88520-000, Lages (SC), Brasil. andrieleg_engf@hotmail.com

5 Engenheiro Florestal, Departamento de Engenharia Florestal, Universidade do Estado de Santa Catarina, Av. Luiz de Camões, 2090, Bairro Conta Dinheiro, CEP 88520-000, Lages (SC), Brasil. diegozech@gmail.com

Recebido para publicação em 11/08/2011 e aceito em 1/08/2012
\end{abstract}


along a tributary of Caeté river, in Alfredo Wagner, state of Santa Catarina, in order to: i) know the structure of trees and flora in this forest, ii) classify the species found according to ecological groups and iii) compare the flora of the study area with other studies in Araucaria forest (FOM), Atlantic Rain Forest (FOD) and the transition area between FOM-FOD of Santa Catarina state. In this fragment, 10 plots of $400 \mathrm{~m}^{2}$ were allocated, where all individual trees with the circumference at breast height $(\mathrm{CBH}$, measured at $1.30 \mathrm{~m}$ above the ground) greater than or equal to $15.7 \mathrm{~cm}$ were measured, marked and identified. The species were classified into the following succession groups: pioneer, climax light-demanding or climax shade-tolerant. The Rectified Correspondence Analysis (DCA) was used for the floristic comparison. The structure of the tree component was described by the density, frequency, dominance and importance value (VI). The results showed elevated species richness (98 species). It was found typical species of FOM, such as Araucaria angustifolia (Bert.) Kuntze, and species characteristics of FOD such as Byrsonima ligustrifolia A.Juss., confirming the study fragment as an area of ecological tension between FOM and FOD. The species with most elevated VI were Psychotria vellosiana Benth., Alsophila setosa Kaulf. and Guatteria australis A.St.Hil. The species with elevated VI, for their considerable representation in the area, are important in the restoration of degraded riparian forests in the region. The species seedlings plantation should be planned observing the group successional of each species, planting pioneer and light-demanding climax species first (e.g. Psychotria vellosiana), followed by, after the shading of the area, shade-tolerant species (e.g. Alsophila setosa e Guatteria australis).

Keywords: Atlantic rain forest; Araucaria forest; floristic; structure.

\section{INTRODUÇÃO}

Florestas ciliares são aquelas localizadas nas margens de rios, riachos, igarapés, lagos, olhos de água e represas, desempenhando importantes funções ambientais, dentre as quais se destacam (BERTONI e MARTINS, 1987; DELITTI, 1989; LIMA, 1989; CARVALHO, 2000): i) a manutenção da estabilidade geológica, evitando desmoronamentos de barrancos e assoreamento de cursos de água, reduzindo os riscos e, ou, a intensidade de enchentes; ii) a manutenção dos recursos hídricos em quantidade e qualidade, por meio da filtragem de poluentes, como defensivos agrícolas e iii) a conservação da biodiversidade e o fluxo gênico da fauna e da flora, pois funcionam como corredores ecológicos, abrigo e fonte de alimentos para a fauna. Em função de sua importância, as florestas ciliares são consideradas como sendo Áreas de Preservação Permanente (APPs) de acordo com o Código Florestal Brasileiro, pela Lei 4.771, de 15/09/1965.

A ocupação desordenada e o desmatamento de ambientes ciliares resultam em alto índice de erosão e assoreamento dos rios, que contribuem para a ocorrência das enchentes (JOLY et al., 2000). Em Santa Catarina, inundações e deslizamentos de terra têm atingido o estado com certa frequência, sendo que, só no final de 2008, foram registrados, concentrado, principalmente, na região do Vale do Itajaí,
109 óbitos e 19 desaparecidos, 78.707 desalojados e desabrigados e 1,5 milhão de pessoas com a vida alterada devido ao grande volume de chuvas (DEFESA CIVIL DO ESTADO DE SANTA CATARINA, 2012). Esses números poderiam ser menores se existisse uma política de incentivo à preservação e à restauração de florestas ciliares e de encostas.

A região do Alto Vale do Itajaí, mais especificamente o município de Alfredo Wagner, caracteriza-se por possuir relevo acidentado com elevado risco de enchentes, pois a sede urbana localiza-se no fundo de um vale e, grande parte desta, em áreas ciliares desmatadas, para onde confluem três rios de forte correnteza e com perfis longitudinais íngremes. O município possui as principais cabeceiras do Rio Itajaí-Açu, dentre elas está a bacia do Rio Caeté, com um alto potencial natural de erosão e com várias áreas em processo de degradação, sendo que a perda de solos chega a $1.987,87$ ton/ha.ano (CHECCHIA, 2005).

Para mitigar esses problemas e diminuir a deposição de sedimentos pela erosão é necessária a reposição da floresta ciliar com espécies adaptadas a este tipo de ambiente. É desejável também, para a manutenção da biodiversidade da fauna e da flora regional, que as espécies utilizadas sejam nativas da região. Para isso, é necessário o conhecimento adequado das espécies que ocorrem naturalmente 
na região e, ao mesmo tempo, que sejam adaptadas ao ambiente ciliar, caracterizado pela ocorrência de alagamentos periódicos em alguns trechos.

Rodrigues e Leitão Filho (2000) apresentaram os resultados de estudos em vegetação de ambientes ciliares de diversas regiões do Brasil, com o propósito de restauração ecológica. $\mathrm{Na}$ obra são apresentados aspectos sobre o ambiente físico e biótico, com destaque para a elevada complexidade das relações ecológicas neste ambiente, que apresentam variações espaciais e temporais. Como estratégias de restauração, o plantio de mudas em ilhas ou área total (KAGEYAMA e GANDARA, 2000) e a implementação de técnicas de nucleação (TRES e REIS, 2009) têm sido empregados frequentemente. Em todas as estratégias, o conhecimento da vegetação local representa uma etapa inicial e fundamental para o sucesso da restauração. A realização de estudos com esse propósito na região do Alto Vale do Rio Itajaí se torna ainda prioritário, quando se avalia o fato de que a estrutura da vegetação dessa região, que pode ser considerada como uma área de transição entre Floresta Ombrófila Mista (FOM) e Floresta Ombrófila Densa (FOD), é pouco conhecida.

Alguns estudos sobre a florística e/ou a estrutura do componente arbóreo de remanescentes florestais foram realizados em Santa Catarina em áreas de FOM (e.g. NEGRELLE e SILVA, 1992; SILVA et al., 1997; FALKENBERG, 2003; FORMENTO et al., 2004; ESKUCHE, 2007; LINGNER et al., 2007; HERRERA et al., 2009; KLAUBERG et al., 2010; FLOSS, 2011; MARTINS-RAMOS, 2011; NASCIMENTO et al., 2011; HIGUCHI et al., 2012; SILVA et al., 2012) e de FOD (e.g. IZA, 2002; CARVALHO, 2003; MANTOVANI et al., 2005; NEGRELLE, 2006; SILVA, 2006; COLONETTI et al., 2009). No entanto, pouco se conhece sobre a composição florística-estrutural em áreas de tensão ecológica dessas duas fitofisionomias (e.g. SCARIOT, 2008).

Assim, para fornecer subsídios para a restauração de fragmentos de Floresta Ciliar do Rio Caeté, SC, na Região do Alto Vale do Rio Itajaí, possibilitando, assim, a melhoria na qualidade da água e a prevenção contra enchentes, este trabalho objetivou: i) conhecer a estrutura e a florística da vegetação arbórea da floresta ciliar de um tributário do Rio Caeté, SC, na Região do Alto Vale do Rio Itajaí; ii) classificar as espécies encontradas nos grupos ecológicos: pioneira, clímax exigente em luz ou clímax tolerante à sombra; iii) comparar a florística da área estudada com outros estudos realizados em FOM, FOD e área de transição entre FOM-FOD em Santa Catarina.

\section{MATERIAL E MÉTODO}

O estudo foi realizado em um remanescente florestal ciliar localizado no município de Alfredo Wagner, SC. O município está localizado a uma latitude de $27^{\circ} 42^{\prime} 01^{\prime \prime}$ Sul e longitude de 49 $20^{\prime} 01^{\prime}$ " Oeste, e está inserido na Bacia Hidrográfica do Rio Itajaí-Açu, com topografia de ondulada a acidentada. As altitudes variam de 450 a $1.200 \mathrm{~m}$ acima do nível do mar, sendo que a área estudada está a uma altitude média de $800 \mathrm{~m}$ (PREFEITURA MUNICIPAL DE ALFREDO WAGNER, 2010). O clima predominante na região é Cfa (mesotérmico úmido, sem estação seca definida, com verões quentes) de acordo com a classificação de Köppen, com a precipitação anual média de $1.500 \mathrm{~mm}$ e a umidade relativa do ar anual variando de 60 a $75 \%$, com 70 a 90 dias de chuva/ano, podendo ocorrer excedentes de 750 a $1.100 \mathrm{~mm} /$ ano. A temperatura média anual é de $19^{\circ} \mathrm{C}$ (PREFEITURA MUNICIPAL DE ALFREDO WAGNER, 2010). Segundo a classificação do IBGE (1992), ocorrem dois tipos de formações florestais na região, a Floresta Ombrófila Mista e a Floresta Ombrófila Densa, caracterizando uma área de tensão ecológica entre estes dois tipos de formações florestais.

Foram alocadas 10 parcelas permanentes de $400 \mathrm{~m}^{2}(20 \times 20 \mathrm{~m})$, totalizando 0,4 ha amostrados. As parcelas foram distribuídas na área de forma sistemática, distanciadas $10 \mathrm{~m}$ entre si, em transectos que procuravam amostrar adequadamente as suas variações ambientais, tais como borda $\mathrm{x}$ interior da floresta e variações topográficas. Dentro de cada parcela, foram medidos, marcados com plaquetas de alumínio e identificados todos os indivíduos arbóreos vivos que apresentaram circunferência a altura do peito (CAP, medido a $1,30 \mathrm{~m}$ do solo) igual ou superior a $15,7 \mathrm{~cm}$ (correspondente a $5 \mathrm{~cm}$ de diâmetro). O CAP foi medido com uma fita métrica, sendo que indivíduos com troncos múltiplos foram medidos quando a raiz da soma dos quadrados dos CAPs foi maior do que $15,7 \mathrm{~cm}$. Os indivíduos não identificados foram coletados para posterior identificação. As identificações foram realizadas por meio de literatura e consultas a especialistas. As espécies foram classificadas nas famílias de acordo com o sistema APG III (ANGIOSPERM PHYLOGENY GROUP, 2009). 
A suficiência da amostragem para determinar a riqueza de espécies nas 10 parcelas foi analisada por meio da elaboração da curva de acumulação de espécies e da extração dos estimadores de Jacknife de primeira e segunda ordem (HELTSHE e FORRESTER, 1983). A curva de acumulação foi construída por meio do método de aleatorização, com 1.000 permutações. A distribuição dos valores de riqueza estimados para as unidades amostrais, por meio das permutações, foi inserida na curva de acumulação de espécies, utilizando gráficos do tipo boxplot. Este procedimento foi realizado por meio do programa estatístico R (R DEVELOPMENT CORE TEAM, 2011) e a biblioteca Vegan (OKSANEN et al., 2009).

Com base nas observações no campo, como, por exemplo, a área de ocorrência na floresta (e.g. sub-bosque, clareiras e bordas), e na literatura existente, as espécies foram classificadas nos grupos sucessionais propostos por Swaine e Whitmore (1988): pioneiras, espécies exigentes de luz direta para germinar e se estabelecer; clímax exigentes de luz, espécies com sementes que germinam sob sombreamento, porém, cujas plantas jovens necessitam de luz para atingir o dossel; clímax tolerantes à sombra, espécies cujas sementes germinam e que crescem sob a sombra, em condições de sub-bosque, e que, dependendo da espécie, pode ou não atingir o dossel na maturidade.

Foram compiladas da literatura científica e de trabalhos ainda não publicados, as listas florísticas de remanescentes em Santa Catarina de Floresta Ombrófila Mista, Floresta Ombrófila Densa, e uma área de transição entre essas duas fitofisionomias, totalizando, junto ao presente estudo, 23 áreas (Tabela 1). Foram extraídas das listas florísticas apenas espécies arborescentes, as quais passaram por uma revisão detalhada a respeito do hábito de crescimento e de sinonímias botânicas. Com o propósito de encontrar padrões florísticos, foi realizada uma Análise de Correspondência Retificada (DCA), onde foram eliminadas as espécies que ocorreram em somente uma área. A análise foi processada por meio do programa estatístico $R(R$ DEVELOPMENT CORE TEAM, 2011), junto com a biblioteca Vegan (OKSANEN et al., 2009).

A estrutura do componente arbóreo foi descrita a partir do cálculo, para cada espécie, dos estimadores quantitativos (MUELLER-DOMBOIS e ELLENBERG, 1974): densidade absoluta e relativa, frequência absoluta e relativa, dominância absoluta e relativa e valor de importância (VI).

\section{RESULTADOS}

Nas parcelas inventariadas foram encontrados 985 indivíduos, totalizando $2.462,5$ ind.ha ${ }^{-1}$, pertencentes a 98 espécies arbóreas, classificadas em 39 famílias botânicas (Tabela 2). Cinco indivíduos não puderam ser identificados devido à dificuldade de acesso ao dossel dessas árvores. As 98 espécies encontradas, classificadas em diferentes grupos sucessionais (pioneira, clímax exigente de luz e clímax tolerante à sombra), representaram $80,13 \%$ da riqueza esperada pelo estimador Jacknife de primeira ordem $(122,3)$ e $81,17 \%$ do estimador de segunda ordem (120,73). A curva de acumulação de espécies (Figura 1) indicou tendência para a estabilização, uma vez que, com o acréscimo da última parcela, ocorreu um aumento médio de apenas 2,74 espécies, correspondentes a $2,80 \%$ das espécies encontradas.

As famílias mais representativas em número de espécies foram Myrtaceae, com 23 espécies, e Lauraceae, com 16 espécies. Considerando todas as famílias, foi possível constatar espécies típicas da Floresta Ombrófila Mista, como Araucaria angustifolia (Bert.) Kuntze (clímax exigente de luz), Ilex microdonta Reissek (clímax tolerante à sombra) e Cinnamodendron dinisii Schwacke (clímax tolerante à sombra), e espécies características da Floresta Ombrófila Densa, como Byrsonima ligustrifolia A.Juss. (clímax exigente de luz), Mollinedia triflora (Spreng.) Tul. (clímax tolerante à sombra) e Myrsine hermogenesii (Jung-Mend. \& Bernacci) M.F.Freitas (clímax exigente de luz), indicando o perfil florístico do fragmento estudado como sendo uma área de tensão ecológica entre as fitofisionomias mencionadas.

Esse padrão é confirmado por meio da ordenação florística do fragmento estudado com demais remanescentes florestais de FOM, FOD e área de transição, pois o presente fragmento ficou localizado entre os agrupamentos de FOM (lado esquerdo do gráfico de ordenação) e os agrupamentos de FOD (lado direito) (Figura 2). O eixo 1, que separou as áreas de FOM, FOD e transição FOM-FOD, obteve autovalor de 0,6577 . O autovalor do eixo 2 , que separou, principalmente, as áreas de FOD do norte de SC (e.g. Itapema e Joinville) das do sul (e.g. Siderópolis), foi de 0,1988 .

Os estimadores fitossociológicos (Tabela 3) foram calculados a fim de se verificar a participação de cada espécie na comunidade. Psychotria vellosiana Benth. foi a espécie que mais se destacou, com valor de importância (VI) de 9,28\%. A domi- 
TABELA 1: Levantamentos florísticos e fitossociológicos dos 23 remanescentes de Floresta Ombrófila Mista (FOM), Floresta Ombrófila Densa (FOD) e áreas de transição entre essas duas fitofisionomias em Santa Catarina.

TABLE 1: Floristic and phytosociological surveys of 23 remnants of Araucaria Forest (FOM), Rain Forest (FOD) and transition areas between these two forest formations, in Santa Catarina state.

\begin{tabular}{|c|c|c|c|c|}
\hline Município & Localidade & Fitofisionomia & Autor(es) & M.A. e N.I \\
\hline Bom Jardim da Serra & $\begin{array}{l}\text { Estâncias Ribeiro e } \\
\text { Machado }\end{array}$ & FOM & Eskuche, 2007 & - \\
\hline Bom Jardim da Serra & Serra do Rio do Rastro & FOM & Falkenberg, 2003 & $\begin{array}{l}\text { Excursões, fanerógamos } \\
\text { férteis }\end{array}$ \\
\hline Caçador & Reserva Embrapa-Epagri & FOM & $\begin{array}{l}\text { Negrelle e Silva, } 1992 \\
\text { Silva et al., } 1997 \\
\text { Lingner et al., } 2007 \\
\text { Herrera et al., } 2009\end{array}$ & $\begin{array}{c}\text { Quadrantes, DAP } \geq 5 \mathrm{~cm} \\
\text { Parcelas, CAP } \geq 60 \mathrm{~cm} \\
\text { Parcelas, CAP } \geq 60 \mathrm{~cm} \\
\text { Parcelas, DAP } \geq 5 \mathrm{~cm}\end{array}$ \\
\hline Campo Belo do Sul & Capatazia Picassos & FOM & Formento et al., 2004 & Parcelas, DAP $\geq 10 \mathrm{~cm}$ \\
\hline Campos Novos & Ibicuí & FOM & $\begin{array}{l}\text { Higuchi et al. dados não } \\
\text { publicados }\end{array}$ & Parcelas, DAP $\geq 5 \mathrm{~cm}$ \\
\hline Lages & Próximo à AMBEV & FOM & $\begin{array}{l}\text { Negrini et al., dados não } \\
\text { publicados }\end{array}$ & Parcelas, DAP $\geq 5 \mathrm{~cm}$ \\
\hline Lages & Guará & FOM & Silva et al., 2012 & Parcelas, DAP $\geq 5 \mathrm{~cm}$ \\
\hline Lages & PARNAMUL & FOM & Klauberg et al., 2010 & Parcelas, $\mathrm{DAP} \geq 5 \mathrm{~cm}$ \\
\hline Lages & Pedras Brancas & FOM & Higuchi et al., 2012 & Parcelas, DAP $\geq 5 \mathrm{~cm}$ \\
\hline Lages & Vale das Trutas & FOM & Nascimento et al., 2011 & Parcelas, DAP $\geq 5 \mathrm{~cm}$ \\
\hline Painel & Farofa & FOM & Higuchi et al., 2013 & Parcelas, DAP $\geq 5 \mathrm{~cm}$ \\
\hline Ponte Serrada & - & $\mathrm{FOM}$ & Floss, 2011 & Parcelas, DAP $\geq 5 \mathrm{~cm}$ \\
\hline Urubici & Serra do Corvo Branco & FOM & Falkenberg, 2003 & $\begin{array}{l}\text { Excursões, fanerógamos } \\
\text { férteis }\end{array}$ \\
\hline Urubici & Morro da Igreja & FOM & Falkenberg, 2003 & $\begin{array}{l}\text { Excursões, fanerógamos } \\
\text { férteis }\end{array}$ \\
\hline Urupema & Fazenda das Nascentes & FOM & Martins-Ramos, 2011 & $\begin{array}{l}\text { Caminhamentos, espécies } \\
\text { arbóreas e arborescentes }\end{array}$ \\
\hline Criciúma & $\begin{array}{l}\text { Parque Ecológico Municipal } \\
\text { José Milanese }\end{array}$ & FOD & Silva, 2006 & Parcelas, DAP $\geq 5 \mathrm{~cm}$ \\
\hline Ilhota & $\begin{array}{l}\text { Parque Botânico do Morro } \\
\text { do Baú }\end{array}$ & FOD & Iza, 2002 & Parcelas, DAP $\geq 5 \mathrm{~cm}$ \\
\hline Itapoá & RPPN Volta Velha & FOD & Negrelle, 2006 & Parcelas, DAP $\geq 5 \mathrm{~cm}$ \\
\hline Joinville & Morro do Timbé & FOD & Carvalho, 2003 & Quadrantes, DAP $\geq 10 \mathrm{~cm}$ \\
\hline $\begin{array}{l}\text { São Pedro de } \\
\text { Alcântara }\end{array}$ & - & FOD & Mantovani et al., 2005 & Parcelas, DAP $\geq 5 \mathrm{~cm}$ \\
\hline Siderópolis & $\begin{array}{l}\text { Entorno da barragem do rio } \\
\text { São Bento }\end{array}$ & FOD & Colonetti et al., 2009 & Parcelas, DAP $\geq 5 \mathrm{~cm}$ \\
\hline Alfredo Wagner & Lomba Alta & $\begin{array}{l}\text { Transição FOM- } \\
\text { FOD }\end{array}$ & Presente estudo & Parcelas, DAP $\geq 5 \mathrm{~cm}$ \\
\hline Rio Negrinho & Fazenda Santa Alice & $\begin{array}{l}\text { Transição FOM- } \\
\text { FOD }\end{array}$ & Scariot, 2008 & $\begin{array}{l}\text { Quadrantes, espécies arbóreas } \\
\text { e arborescentes }\end{array}$ \\
\hline
\end{tabular}

M.A.: método de amostragem; N.I.: nível de inclusão; DAP: diâmetro a altura do peito, medido a 1,30 m do solo; CAP: circunferência a altura do peito, medido a $1,30 \mathrm{~m}$ do solo; H: altura total. 
nância (DoR $=13,97 \%$ ), que expressa a área basal dos indivíduos, foi o parâmetro que teve maior contribuição no seu alto valor de VI. Alsophila setosa Kaulf. foi a espécie de maior densidade na área estudada ( $\mathrm{DR}=13,29 \%$ ), o que contribuiu para que esta tivesse o segundo maior VI $(7,96 \%)$. Com o terceiro maior VI $(4,70 \%)$ está Guatteria australis A.St.-Hil., sendo que a frequência de $100 \%$ nas unidades amostrais foi o parâmetro que mais contribuiu para essa posição.

TABELA 2: Composição florística de um remanescente florestal localizado em área de transição entre Floresta Ombrófila Mista e Floresta Ombrófila Densa em Alfredo Wagner, SC, e seu respectivo grupo sucessional (GS), sendo $\mathrm{P}=$ pioneira, $\mathrm{CL}=$ clímax exigente de luz, $\mathrm{CS}=$ clímax tolerante à sombra.

TABLE 2: Floristic species list of a forest remnant located in a transitional area between Araucaria forest and rain forest, in the municipality of Alfredo Wagner, Santa Catarina state, and their respective successional group (GS), where $\mathrm{P}$ $=$ pioneer, $\mathrm{CL}=$ Light-demanding climax, $\mathrm{CS}=$ Shade-tolerant climax.

\begin{tabular}{cc}
\hline Família/Nome Científico & GS \\
\hline ANNONACEAE & \\
Guatteria australis A.St.-Hil. & $\mathrm{CS}$ \\
AQUIFOLIACEAE & \\
Ilex brevicuspis Reissek & $\mathrm{CS}$ \\
Ilex dumosa Reissek & $\mathrm{CS}$ \\
Ilex microdonta Reissek & $\mathrm{CS}$ \\
Ilex paraguariensis A.St.-Hil. & $\mathrm{CS}$ \\
Ilex theezans Mart. ex Reissek & $\mathrm{CS}$ \\
ARALIACEAE & \\
Schefflera angustissima (Marchal) Frodin & $\mathrm{CS}$ \\
ARAUCARIACEAE & \\
Araucaria angustifolia (Bert.) Kuntze & $\mathrm{CL}$ \\
ASTERACEAE & \\
Asteraceae sp.1 & - \\
Gochnatia polymorpha (Less.) Cabrera & $\mathrm{P}$ \\
Vernonanthura discolor (Spreng.) H.Rob. & $\mathrm{P}$ \\
BIGNONIACEAE & \\
Jacaranda puberula Cham. & $\mathrm{CL}$ \\
Jacaranda micrantha Cham. & $\mathrm{CL}$ \\
\hline
\end{tabular}

Continua $\ldots$

\section{DISCUSSÃO}

Os estimadores de riqueza Jacknife de primeira e segunda ordem indicaram que o levantamento contemplou a maior parte da riqueza potencial da área estudada. Além disso, a curva de acumulação de espécies, com pequeno acréscimo de espécies com a alocação da última parcela, também demonstrou que a amostragem foi adequada para a caracterização florística da área.

TABELA 2: Continuação ...

TABLE 2: Continued ...

\begin{tabular}{|c|c|}
\hline Família/Nome Científico & GS \\
\hline \multicolumn{2}{|l|}{ CANELLACEAE } \\
\hline Cinnamodendron dinisii Schwacke & CS \\
\hline CARDIOPTERIDACEAE & \\
\hline Citronella paniculata (Mart.) R.A.Howard & $\mathrm{CS}$ \\
\hline \multicolumn{2}{|l|}{ CLETHRACEAE } \\
\hline Clethra scabra Pers. & $\mathrm{CL}$ \\
\hline \multicolumn{2}{|l|}{ CUNONIACEAE } \\
\hline Lamanonia ternata Vell. & $\mathrm{CL}$ \\
\hline \multicolumn{2}{|l|}{ CYATHEACEAE } \\
\hline Alsophila setosa Kaulf. & $\mathrm{CS}$ \\
\hline \multicolumn{2}{|l|}{ DICKSONIACEAE } \\
\hline Dicksonia sellowiana Hook. & $\mathrm{CS}$ \\
\hline \multicolumn{2}{|l|}{ ELAEOCARPACEAE } \\
\hline Sloanea monosperma Vell. & $\mathrm{CS}$ \\
\hline \multicolumn{2}{|l|}{ ERYTHROXYLACEAE } \\
\hline Erythroxylum deciduum A.St.-Hil. & $\mathrm{CL}$ \\
\hline \multicolumn{2}{|l|}{ EUPHORBIACEAE } \\
\hline Alchornea triplinervia (Spreng.) Müll.Arg. & $\mathrm{CL}$ \\
\hline Sapium glandulosum (L.) Morong & $\mathrm{CL}$ \\
\hline \multicolumn{2}{|l|}{ FABACEAE } \\
\hline Inga virescens Benth. & $\mathrm{CL}$ \\
\hline Machaerium stipitatum (DC.) Vogel & $\mathrm{CL}$ \\
\hline \multicolumn{2}{|l|}{ LAMIACEAE } \\
\hline Aegiphila sellowiana Cham. & $\mathrm{CL}$ \\
\hline \multicolumn{2}{|l|}{ LAURACEAE } \\
\hline Aiouea cf acarodomatifera Kosterm. & $\mathrm{CS}$ \\
\hline Cinnamomum cf riedelianum Kosterm. & $\mathrm{CS}$ \\
\hline Cinnamomum glaziovii (Mez) Kosterm. & $\mathrm{CS}$ \\
\hline Cryptocarya aschersoniana $\mathrm{Mez}$ & $\mathrm{CL}$ \\
\hline Cryptocarya moschata Nees \& Mart. ex Nees & $\mathrm{CL}$ \\
\hline Lauraceae sp. 1 & - \\
\hline Lauraceae sp. 2 & - \\
\hline
\end{tabular}

Continua ... 
TABELA 2: Continuação ...

TABLE 2: Continued ...

\begin{tabular}{|c|c|}
\hline Família/Nome Científico & GS \\
\hline Nectandra cf membranacea (Sw.) Griseb. & $\mathrm{CS}$ \\
\hline Nectandra grandiflora Nees & $\mathrm{CS}$ \\
\hline Ocotea cf elegans Mez & $\mathrm{CS}$ \\
\hline Ocotea lanata (Nees) Mez & $\mathrm{CS}$ \\
\hline Ocotea laxa (Nees) Mez & $\mathrm{CL}$ \\
\hline Ocotea odorifera (Vell.) Rohwer & $\mathrm{CS}$ \\
\hline Ocotea puberula (Rich.) Nees & $\mathrm{CL}$ \\
\hline Ocotea pulchella Mart. & $\mathrm{CS}$ \\
\hline $\begin{array}{l}\text { Persea willdenowii Kosterm. } \\
\text { MALPIGHIACEAE }\end{array}$ & $\mathrm{CL}$ \\
\hline $\begin{array}{l}\text { Byrsonima ligustrifolia A.Juss. } \\
\text { MELASTOMATACEAE }\end{array}$ & $\mathrm{CL}$ \\
\hline Miconia pusilliflora (DC.) Triana & $\mathrm{P}$ \\
\hline $\begin{array}{c}\text { Tibouchina sellowiana (Cham.) Cogn. } \\
\text { MELIACEAE }\end{array}$ & $\mathrm{P}$ \\
\hline Cabralea canjerana (Vell.) Mart. & $\mathrm{CL}$ \\
\hline $\begin{array}{l}\text { Cedrela fissilis Vell. } \\
\text { MONIMIACEAE }\end{array}$ & $\mathrm{CL}$ \\
\hline $\begin{array}{c}\text { Mollinedia triflora (Spreng.) Tul. } \\
\text { MORACEAE }\end{array}$ & $\mathrm{CS}$ \\
\hline Ficus luschnathiana (Miq.) Miq. & $\mathrm{CL}$ \\
\hline $\begin{array}{c}\text { Sorocea bonplandii (Baill.) W.C.Burger et al. } \\
\text { MYRTACEAE }\end{array}$ & $\mathrm{CS}$ \\
\hline Blepharocalyx salicifolius (Kunth) O.Berg & $\mathrm{CS}$ \\
\hline Calyptranthes grandifolia O.Berg & $\mathrm{CS}$ \\
\hline Campomanesia xanthocarpa O.Berg & $\mathrm{CS}$ \\
\hline Eugenia bacopari D.Legrand & $\mathrm{CL}$ \\
\hline Eugenia burkartiana (D.Legrand) D.Legrand & $\mathrm{CS}$ \\
\hline Eugenia brasiliensis Lam. & $\mathrm{CS}$ \\
\hline Eugenia involucrata DC. & $\mathrm{CL}$ \\
\hline Eugenia neoverrucosa Sobral & $\mathrm{CS}$ \\
\hline $\begin{array}{c}\text { Myrceugenia miersiana (Gardner) D.Legrand \& } \\
\text { Kausel }\end{array}$ & $\mathrm{CL}$ \\
\hline Myrceugenia sp. & - \\
\hline Myrcia hartwegiana (O.Berg) Kiaersk. & $\mathrm{CL}$ \\
\hline Myrcia hatschbachii D.Legrand & $\mathrm{CL}$ \\
\hline Myrcia hebepetala DC. & $\mathrm{CS}$ \\
\hline Myrcia palustris DC. & $\mathrm{CL}$ \\
\hline Myrcia retorta Cambess. & $\mathrm{CS}$ \\
\hline Myrcia splendens (Sw.) DC. & $\mathrm{CL}$ \\
\hline Myrcia undulata O.Berg & $\mathrm{CS}$ \\
\hline Myrciaria floribunda (H.West ex Willd.) O.Berg & $\mathrm{CS}$ \\
\hline Myrtaceae sp. 1 & - \\
\hline Myrtaceae sp. 2 & - \\
\hline
\end{tabular}

TABELA 2: Continuação ...

TABLE 2: Continued ...

\begin{tabular}{cc}
\hline Família/Nome Científico & GS \\
\hline Pimenta pseudocaryophyllus (Gomes) Landrum & $\mathrm{CL}$ \\
Psidium longipetiolatum D.Legrand & $\mathrm{CL}$ \\
Psidium sp. & - \\
OLEACEAE & \\
Chionanthus trichotomus (Vell.) P.S.Green & $\mathrm{CS}$
\end{tabular}

Chionanthus trichotomus (Vell.) P.S.Green CS PRIMULACEAE

Myrsine coriacea (Sw.) Roem. \& Schult. CL

Myrsine gardneriana A.DC. CL

Myrsine hermogenesii (Jung-Mend. \& Bernacci) CL M.F.Freitas

Myrsine umbellata Mart.

CL

PROTEACEAE

Roupala montana Aubl.

CL

ROSACEAE

Prunus myrtifolia (L.) Urb.

CL

RUBIACEAE

Cordiera concolor (Cham.) Kuntze CL

Psychotria vellosiana Benth.

Rubiaceae sp. 1

RUTACEAE

Esenbeckia grandiflora Mart.

CS

SALICACEAE

Casearia decandra Jacq. CS

Casearia obliqua Spreng. $\quad$ CS

Casearia sylvestris Sw. CL

Xylosma prockia (Turcz.) Turcz. CL

SAPINDACEAE

Allophylus edulis (A.St.-Hil. et al.) Radlk. CL

Cupania vernalis Cambess. $\quad \mathrm{CL}$

Matayba elaeagnoides Radlk. $\quad$ CL

SAPOTACEAE

Chrysophyllum marginatum (Hook. \& Arn.) Radlk. CL SIMAROUBACEAE

Picrasma crenata (Vell.) Eichler

CL

SOLANACEAE

Solanum mauritianum Scop.

STYRACACEAE

Styrax acuminatus Pohl

SYMPLOCACEAE

Symplocos tenuifolia Brand

THEACEAE

Laplacea acutifolia (Wawra) Kobuski CL

WINTERACEAE

Drimys brasiliensis Miers

CS 


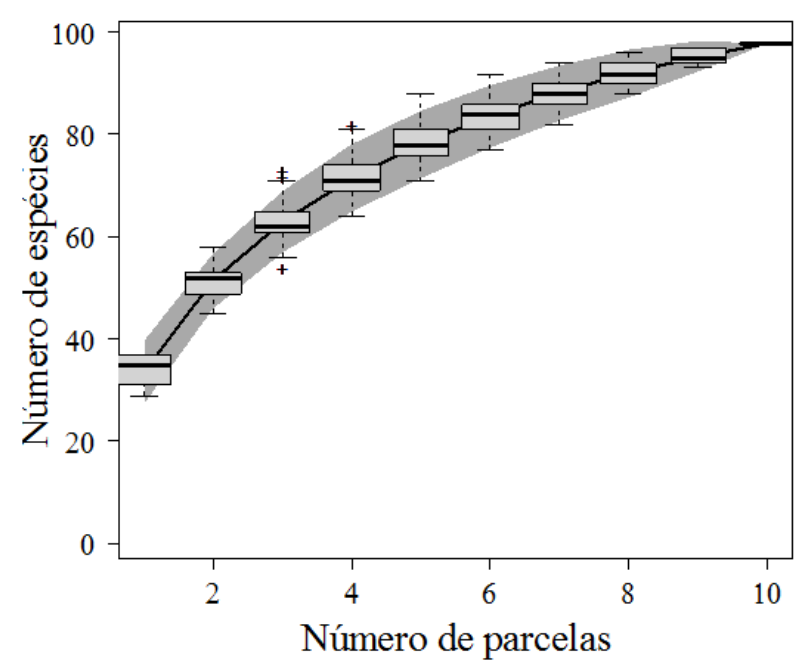

FIGURA 1: Curva de acumulação de espécies do componente arbóreo de um remanescente florestal localizado em área de transição entre Floresta Ombrófila Mista e Floresta Ombrófila Densa, em Alfredo Wagner, SC. A distribuição dos valores de riqueza de acordo com a acumulação das unidades amostrais é ilustrado por meio de gráficos do tipo boxplot.

FIGURE 1: Tree species accumulation-curve for a forest remnant located in a transitional area between Araucaria forest and rain forest, in the municipality of Alfredo Wagner, Santa Catarina state. The distribution of richness values according to the accumulation of sampling plots is showed by boxplot.

A composição florística, com elevada riqueza das famílias Myrtaceae e Lauraceae, caracterizou uma área de transição de Floresta Ombrófila Mista (FOM) e Floresta Ombrófila Densa (FOD). A área de tensão ecológica é também confirmada verificando-se a presença de espécies exclusivas de ambas fitofisionomias e pela análise de ordenação realizada (DCA).

O eixo 1 da DCA, que separou as áreas de FOM, FOD e transição FOM-FOD, obteve elevado autovalor, indicando que houve alta substituição de espécies ao longo dos gradientes ambientais que definem esse eixo. Isso ocorreu devido ao grande número de espécies exclusivas de FOM e de FOD. $\mathrm{O}$ fato da área estudada se localizar entre os dois agrupamentos (de FOM e de FOD) confirma sua característica de compartilhar espécies de ambas fi- tofisionomias. Apesar de não avaliada, a ordenação ao longo do eixo 1 evidencia, também, a influência do piso altitudinal, com áreas montanas e alto-montanas situadas no extremo à esquerda no gráfico e áreas situadas próximas ao nível do mar ocupando o extremo direito do gráfico. Além disso, ressalta-se a importância de bacias hidrográficas na definição dos agrupamentos, com FOD e áreas de transição ocupando bacias de rios que correm para o leste, em direção ao oceano, e FOM presentes nas bacias dos rios que correm para o oeste, no sentido do interior do estado. O eixo 2 da DCA, de menor autovalor, demonstrou uma menor substituição de espécies. Neste caso, o eixo 2 separou as áreas dentro das mesmas fitofisionomias. No caso das áreas de FOD, este eixo representou um gradiente latitudinal entre as áreas do norte e sul do Estado.

Assim, em um futuro projeto de restauração florestal na região, devem ser utilizadas espécies tanto de FOM como de FOD. Além disso, deve-se observar o grupo sucessional das espécies, plantando-se as espécies pioneiras e clímax exigentes de luz em um primeiro momento, seguidas, quando houver o sombreamento da área, das espécies clímax tolerante à sombra. Também é importante observar em qual o micro-habitat ocorre cada espécie. Como se trata de área ciliar, é importante observar a ocorrência de locais inundáveis ou não. Além disso, na presença de inundação, se essa é de ocorrência periódica e não permanente, como nos ambientes aluviais, ou se é de caráter permanente, com solos saturados durante quase ou todo o ano, caracterizando um ambiente paludoso.

Dentre as espécies encontradas, Silva et al. (2007) citam Casearia sylvestris Sw. como de ocorrência comum em áreas inundáveis. Das 35 áreas inundáveis avaliadas pelos autores nas regiões sul e sudeste do Brasil, Casearia sylvestris foi encontrada em 18, obtendo ocorrência não preferencial por determinado tipo de habitat inundável (aluvial ou paludoso). Outras espécies encontradas no presente estudo, como Prunus myrtifolia (L.) Urb., Chrysophyllum marginatum (Hook. \& Arn.) Radlk., Blepharocalyx salicifolius (Kunth) O.Berg, Sapium glandulosum (L.) Morong, Myrsine umbellata Mart., Myrcia splendens (Sw.) DC., Alchornea triplinervia (Spreng.) Müll.Arg., Roupala montana Aubl. e Cabralea canjerana (Vell.) Mart., também foram encontradas como espécies comuns em áreas inundáveis (habitat não preferencial) estudadas por Silva et al. (2007), sendo, por isso, espécies indicadas para a recomposição de florestas ciliares degrada- 


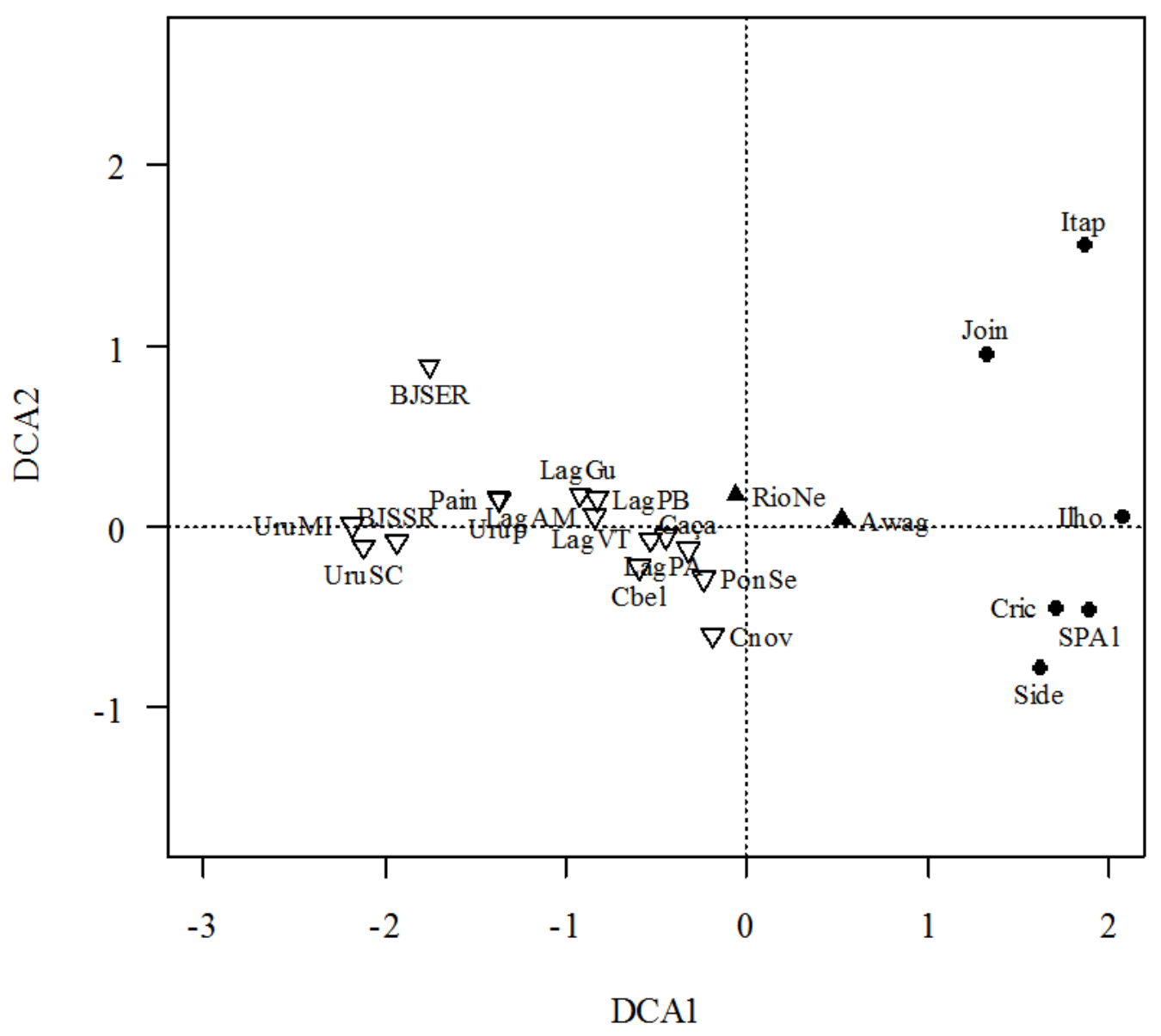

FIGURA 2: Ordenação por meio de uma Análise de Correspondência Retificada (DCA) de 23 remanescentes localizados no Estado de Santa Catarina de Floresta Ombrófila Mista (FOM - triângulos invertidos), Floresta Ombrófila Densa (FOD - círculos) e áreas de transição entre FOM-FOD (triângulos). BJSER = Bom Jardim da Serra - Estâncias Ribeiro e Machado; BJSSR = Bom Jardim da Serra - Serra do Rio do Rastro; UruMI = Urubici - Morro da Igreja; UruSC = Urubici - Serra do Corvo Branco; Pain = Painel; Urup = Urupema; LagAM = Lages - próximo à AMBEV; LagGu = Lages - Guará; LagVT = Lages - Vale das Trutas; LagPB = Lages Pedras Brancas; LagPA $=$ Lages $=$ PARNAMUL; Caça $=$ Caçador; Cbel $=$ Campo Belo do Sul; PonSe $=$ Ponte Serrada $;$ Cnov $=$ Campos Novos; RioNe $=$ Rio Negrinho; Awag $=$ Alfredo Wagner; Itap = Itapoá; Join = Joinville; Ilho $=$ Ilhota; Cric $=$ Criciúma; SPAl $=$ São Pedro de Alcântara; Side $=$ Siderópolis.

FIGURE 2: Ordination by Rectified Correspondence Analysis (DCA) of 23 remnants located in Santa Catarina State of Araucaria forest (FOM - inverted triangles), Rain Forest (FOD - circles) and transition areas between FOM-FOD (triangles). BJSER = Bom Jardim da Serra - Estâncias Ribeiro e Machado; BJSSR = Bom Jardim da Serra - Serra do Rio do Rastro; UruMI = Urubici - Morro da Igreja; UruSC = Urubici - Serra do Corvo Branco; Pain = Painel; Urup = Urupema; LagAM = Lages - próximo à AMBEV; LagGu = Lages - Guará; LagVT = Lages - Vale das Trutas; LagPB = Lages - Pedras Brancas; LagPA = Lages = PARNAMUL; Caça = Caçador; Cbel = Campo Belo do Sul; PonSe = Ponte Serrada; Cnov = Campos Novos; RioNe $=$ Rio Negrinho; Awag = Alfredo Wagner; Itap = Itapoá; Join = Joinville; Ilho = Ilhota; Cric $=$ Criciúma; $\mathrm{SPAl}=$ São Pedro de Alcântara; Side $=$ Siderópolis. 
das sujeitas a inundações. Espécies como Casearia decandra Jacq., Sorocea bonplandii (Baill.) W.C.Burger et al., Cupania vernalis Cambess., Matayba elaeagnoides Radlk., Allophylus edulis (A.St.-Hil. et al.) Radlk. e Campomanesia xanthocarpa O.Berg foram consideradas por Silva et al. (2007) abundantes em florestas inundáveis e preferenciais de ambientes aluviais e são, portanto, indicadas também para recomporem florestas ciliares degradadas, sujeitas a inundações.

Além de considerar esses fatores, é importante observar as espécies de maior importância na área, para indicá-las em plantios de restauração. $\mathrm{O}$ alto valor de importância de Psychotria vellosiana, associado à alta dominância, indicou indivíduos de grande porte na área estudada, sendo espécies importantes na estrutura da floresta. Alsophila setosa, também de alto valor de importância, foi a espécie de maior densidade na área, sendo também indicada em plantios de restauração na região, podendo ser plantadas em alta densidade. Já Guatteria australis obteve alto valor de importância devido a sua alta frequência, demonstrando ser uma espécie não preferencial por habitat na área estudada, podendo ser plantado em diferentes condições ambientais de florestas ciliares da região.

TABELA 3: Estimadores fitossociológicos das populações das espécies arbóreas encontradas em um fragmento florestal localizado em área de transição entre Floresta Ombrófila Mista e Floresta Ombrófila Densa em Alfredo Wagner, SC, ordenadas pelo Valor de Importância (VI). DA = densidade absoluta (ind. ha $\left.^{-1}\right) ; \mathrm{DR}=$ densidade relativa (\%); FA = frequência absoluta (\%); FR $=$ frequência relativa $(\%) ;$ DoA $=$ dominância absoluta $\left(\mathrm{m}^{2}\right.$ ha-1 $) ;$ DoR $=$ dominância relativa $(\%)$.

TABLE 3: Phyto-sociological estimators of tree species populations found in a forest fragment located in a transitional area between Araucaria forest and rain forest in the municipality of Alfredo Wagner, Santa Catarina state, ranked by importance value (VI). DA = absolute density (ind. $\left.\mathrm{ha}^{-1}\right) ; \mathrm{DR}=$ relative density $(\%) ; \mathrm{FA}=$ absolute frequency $(\%) ; \mathrm{FR}=$ relative frequency $(\%)$; DoA $=$ absolute dominance $\left(\mathrm{m}^{2} \mathrm{ha}^{-1}\right) ;$ DoR $=$ relative dominance $(\%)$.

\begin{tabular}{lccccccc}
\hline Espécie & DA & DR & FA & FR & DoA & DoR & VI \\
\hline Psychotria vellosiana & 270 & 11,21 & 90,00 & 2,65 & 4,81 & 13,97 & 9,28 \\
Alsophila setosa & 320 & 13,29 & 50,00 & 1,47 & 3,14 & 9,13 & 7,96 \\
Guatteria australis & 120 & 4,98 & 100,00 & 2,94 & 2,13 & 6,19 & 4,70 \\
Myrsine umbellata & 135 & 5,61 & 100,00 & 2,94 & 1,84 & 5,34 & 4,63 \\
Ocotea odorifera & 117,5 & 4,88 & 90,00 & 2,65 & 1,15 & 3,35 & 3,63 \\
Myrcia splendens & 110 & 4,57 & 70,00 & 2,06 & 1,16 & 3,38 & 3,33 \\
Casearia obliqua & 57,5 & 2,39 & 90,00 & 2,65 & 1,40 & 4,06 & 3,03 \\
Cryptocarya aschersoniana & 57,5 & 2,39 & 90,00 & 2,65 & 0,59 & 1,72 & 2,25 \\
Cryptocarya moschata & 52,5 & 2,18 & 60,00 & 1,76 & 0,90 & 2,62 & 2,19 \\
Mollinedia triflora & 75 & 3,12 & 70,00 & 2,06 & 0,48 & 1,39 & 2,19 \\
Vernonanthura discolor & 37,5 & 1,56 & 70,00 & 2,06 & 0,95 & 2,75 & 2,12 \\
Casearia sylvestris & 50 & 2,08 & 80,00 & 2,35 & 0,36 & 1,06 & 1,83 \\
Ilex paraguariensis & 25 & 1,04 & 70,00 & 2,06 & 0,76 & 2,20 & 1,77 \\
Myrcia retorta & 27,5 & 1,14 & 40,00 & 1,18 & 1,02 & 2,97 & 1,76 \\
Clethra scabra & 25 & 1,04 & 70,00 & 2,06 & 0,71 & 2,08 & 1,72 \\
Machaerium stipitatum & 25 & 1,04 & 60,00 & 1,76 & 0,77 & 2,24 & 1,68 \\
Blepharocalyx salicifolius & 40 & 1,66 & 60,00 & 1,76 & 0,52 & 1,51 & 1,65 \\
Alchornea triplinervia & 20 & 0,83 & 50,00 & 1,47 & 0,86 & 2,50 & 1,60 \\
Myrcia undulata & 45 & 1,87 & 50,00 & 1,47 & 0,44 & 1,27 & 1,54 \\
Roupala montana & 42,5 & 1,77 & 60,00 & 1,76 & 0,30 & 0,88 & 1,47 \\
Myrcia hebepetala & 30 & 1,25 & 70,00 & 2,06 & 0,33 & 0,96 & 1,42 \\
\hline & & & & & & & Con \\
\hline
\end{tabular}


TABELA 3: Continuação ...

TABLE 3: Cotninued ...

\begin{tabular}{|c|c|c|c|c|c|c|c|}
\hline Espécie & DA & DR & FA & FR & DoA & DoR & VI \\
\hline Casearia decandra & 32,5 & 1,35 & 70,00 & 2,06 & 0,28 & 0,81 & 1,41 \\
\hline Cedrela fissilis & 10 & 0,42 & 20,00 & 0,59 & 1,09 & 3,17 & 1,39 \\
\hline Cabralea canjerana & 35 & 1,45 & 60,00 & 1,76 & 0,15 & 0,43 & 1,22 \\
\hline Ocotea laxa & 30 & 1,25 & 60,00 & 1,76 & 0,19 & 0,56 & 1,19 \\
\hline Eugenia neoverrucosa & 27,5 & 1,14 & 60,00 & 1,76 & 0,22 & 0,64 & 1,18 \\
\hline Ilex theezans & 30 & 1,25 & 60,00 & 1,76 & 0,17 & 0,49 & 1,17 \\
\hline Myrcia hatschbachii & 25 & 1,04 & 50,00 & 1,47 & 0,32 & 0,92 & 1,14 \\
\hline Drimys brasiliensis & 20 & 0,83 & 50,00 & 1,47 & 0,28 & 0,80 & 1,04 \\
\hline Ilex dumosa & 17,5 & 0,73 & 60,00 & 1,76 & 0,21 & 0,60 & 1,03 \\
\hline Erythroxylum deciduum & 17,5 & 0,73 & 40,00 & 1,18 & 0,40 & 1,17 & 1,02 \\
\hline Matayba elaeagnoides & 20 & 0,83 & 50,00 & 1,47 & 0,26 & 0,76 & 1,02 \\
\hline Schefflera angustissima & 20 & 0,83 & 40,00 & 1,18 & 0,28 & 0,81 & 0,94 \\
\hline Ocotea puberula & 15 & 0,62 & 50,00 & 1,47 & 0,20 & 0,58 & 0,89 \\
\hline Sorocea bonplandii & 17,5 & 0,73 & 50,00 & 1,47 & 0,14 & 0,40 & 0,87 \\
\hline Indivíduos não identificados & 12,5 & 0,52 & 30,00 & 0,88 & 0,34 & 0,99 & 0,80 \\
\hline Myrsine hermogenesii & 15 & 0,62 & 50,00 & 1,47 & 0,09 & 0,25 & 0,78 \\
\hline Eugenia brasiliensis & 15 & 0,62 & 40,00 & 1,18 & 0,11 & 0,31 & 0,70 \\
\hline Chionanthus trichotomus & 7,5 & 0,31 & 30,00 & 0,88 & 0,31 & 0,91 & 0,70 \\
\hline Eugenia bacopari & 15 & 0,62 & 30,00 & 0,88 & 0,18 & 0,51 & 0,67 \\
\hline Byrsonima ligustrifolia & 15 & 0,62 & 30,00 & 0,88 & 0,15 & 0,43 & 0,65 \\
\hline Cordiera concolor & 15 & 0,62 & 40,00 & 1,18 & 0,05 & 0,14 & 0,65 \\
\hline Allophylus edulis & 15 & 0,62 & 20,00 & 0,59 & 0,24 & 0,69 & 0,63 \\
\hline Ocotea cf elegans & 12,5 & 0,52 & 30,00 & 0,88 & 0,13 & 0,38 & 0,59 \\
\hline Symplocos tenuifolia & 7,5 & 0,31 & 30,00 & 0,88 & 0,18 & 0,53 & 0,58 \\
\hline Sloanea monosperma & 5 & 0,21 & 20,00 & 0,59 & 0,30 & 0,88 & 0,56 \\
\hline Lamanonia ternata & 7,5 & 0,31 & 20,00 & 0,59 & 0,26 & 0,75 & 0,55 \\
\hline Cinnamomum cf riedelianum & 10 & 0,42 & 30,00 & 0,88 & 0,10 & 0,29 & 0,53 \\
\hline Nectandra grandiflora & 7,5 & 0,31 & 30,00 & 0,88 & 0,12 & 0,35 & 0,51 \\
\hline Myrsine coriacea & 7,5 & 0,31 & 30,00 & 0,88 & 0,10 & 0,28 & 0,49 \\
\hline Myrceugenia sp. & 15 & 0,62 & 20,00 & 0,59 & 0,09 & 0,26 & 0,49 \\
\hline Psidium longipetiolatum & 7,5 & 0,31 & 30,00 & 0,88 & 0,09 & 0,27 & 0,49 \\
\hline Persea willdenowii & 2,5 & 0,10 & 10,00 & 0,29 & 0,33 & 0,95 & 0,45 \\
\hline Ilex microdonta & 7,5 & 0,31 & 30,00 & 0,88 & 0,04 & 0,12 & 0,44 \\
\hline Nectandra cf membranacea & 5 & 0,21 & 20,00 & 0,59 & 0,14 & 0,40 & 0,40 \\
\hline Cupania vernalis & 10 & 0,42 & 20,00 & 0,59 & 0,06 & 0,16 & 0,39 \\
\hline Eugenia burkartiana & 7,5 & 0,31 & 20,00 & 0,59 & 0,08 & 0,24 & 0,38 \\
\hline Jacaranda micrantha & 10 & 0,42 & 10,00 & 0,29 & 0,14 & 0,42 & 0,38 \\
\hline Lauraceae sp. 2 & 5 & 0,21 & 20,00 & 0,59 & 0,11 & 0,32 & 0,37 \\
\hline Eugenia involucrata & 7,5 & 0,31 & 20,00 & 0,59 & 0,07 & 0,19 & 0,36 \\
\hline Dicksonia sellowiana & 7,5 & 0,31 & 10,00 & 0,29 & 0,16 & 0,46 & 0,35 \\
\hline Esenbeckia grandiflora & 10 & 0,42 & 10,00 & 0,29 & 0,10 & 0,30 & 0,34 \\
\hline
\end{tabular}


TABELA 3: Continuação ...

TABLE 3: Cotninued ...

\begin{tabular}{|c|c|c|c|c|c|c|c|}
\hline Espécie & DA & DR & FA & FR & DoA & DoR & VI \\
\hline Lauraceae sp. 1 & 7,5 & 0,31 & 20,00 & 0,59 & 0,04 & 0,11 & 0,34 \\
\hline Sapium glandulosum & 5 & 0,21 & 20,00 & 0,59 & 0,07 & 0,19 & 0,33 \\
\hline Cinnamomum glaziovii & 5 & 0,21 & 20,00 & 0,59 & 0,05 & 0,16 & 0,32 \\
\hline Pimenta pseudocaryophyllus & 5 & 0,21 & 20,00 & 0,59 & 0,05 & 0,16 & 0,32 \\
\hline Ficus luschnathiana & 5 & 0,21 & 20,00 & 0,59 & 0,05 & 0,13 & 0,31 \\
\hline Myrcia palustris & 5 & 0,21 & 20,00 & 0,59 & 0,04 & 0,11 & 0,30 \\
\hline Myrsine gardneriana & 5 & 0,21 & 20,00 & 0,59 & 0,04 & 0,11 & 0,30 \\
\hline Tibouchina sellowiana & 5 & 0,21 & 20,00 & 0,59 & 0,04 & 0,11 & 0,30 \\
\hline Picrasma crenata & 5 & 0,21 & 20,00 & 0,59 & 0,03 & 0,10 & 0,30 \\
\hline Ilex brevicuspis & 2,5 & 0,10 & 10,00 & 0,29 & 0,17 & 0,49 & 0,30 \\
\hline Calyptranthes grandifolia & 5 & 0,21 & 20,00 & 0,59 & 0,03 & 0,09 & 0,30 \\
\hline Aiouea cf acarodomatifera & 5 & 0,21 & 20,00 & 0,59 & 0,03 & 0,09 & 0,29 \\
\hline Myrtaceae sp. 2 & 5 & 0,21 & 20,00 & 0,59 & 0,03 & 0,08 & 0,29 \\
\hline Rubiaceae sp. 1 & 5 & 0,21 & 10,00 & 0,29 & 0,13 & 0,37 & 0,29 \\
\hline Cinnamodendron dinisii & 5 & 0,21 & 20,00 & 0,59 & 0,02 & 0,05 & 0,28 \\
\hline Myrceugenia miersiana & 5 & 0,21 & 20,00 & 0,59 & 0,01 & 0,04 & 0,28 \\
\hline Miconia pusilliflora & 7,5 & 0,31 & 10,00 & 0,29 & 0,05 & 0,13 & 0,25 \\
\hline Asteraceae sp. 1 & 2,5 & 0,10 & 10,00 & 0,29 & 0,11 & 0,33 & 0,24 \\
\hline Laplacea acutifolia & 2,5 & 0,10 & 10,00 & 0,29 & 0,10 & 0,29 & 0,23 \\
\hline Campomanesia xanthocarpa & 5 & 0,21 & 10,00 & 0,29 & 0,04 & 0,10 & 0,20 \\
\hline Inga virescens & 2,5 & 0,10 & 10,00 & 0,29 & 0,07 & 0,20 & 0,20 \\
\hline Solanum mauritianum & 5 & 0,21 & 10,00 & 0,29 & 0,02 & 0,07 & 0,19 \\
\hline Gochnatia polymorpha & 2,5 & 0,10 & 10,00 & 0,29 & 0,06 & 0,17 & 0,19 \\
\hline Aegiphila sellowiana & 2,5 & 0,10 & 10,00 & 0,29 & 0,05 & 0,15 & 0,18 \\
\hline Citronella paniculata & 5 & 0,21 & 10,00 & 0,29 & 0,01 & 0,03 & 0,18 \\
\hline Myrcia hartwegiana & 2,5 & 0,10 & 10,00 & 0,29 & 0,04 & 0,11 & 0,17 \\
\hline Araucaria angustifolia & 2,5 & 0,10 & 10,00 & 0,29 & 0,04 & 0,11 & 0,17 \\
\hline Ocotea pulchella & 2,5 & 0,10 & 10,00 & 0,29 & 0,03 & 0,09 & 0,16 \\
\hline Styrax acuminatus & 2,5 & 0,10 & 10,00 & 0,29 & 0,03 & 0,09 & 0,16 \\
\hline Xylosma prockia & 2,5 & 0,10 & 10,00 & 0,29 & 0,02 & 0,05 & 0,15 \\
\hline Prunus myrtifolia & 2,5 & 0,10 & 10,00 & 0,29 & 0,01 & 0,04 & 0,15 \\
\hline Myrciaria floribunda & 2,5 & 0,10 & 10,00 & 0,29 & 0,01 & 0,04 & 0,15 \\
\hline Jacaranda puberula & 2,5 & 0,10 & 10,00 & 0,29 & 0,01 & 0,04 & 0,14 \\
\hline Ocotea lanata & 2,5 & 0,10 & 10,00 & 0,29 & 0,01 & 0,03 & 0,14 \\
\hline Psidium sp. & 2,5 & 0,10 & 10,00 & 0,29 & 0,01 & 0,03 & 0,14 \\
\hline Myrtaceae sp. 1 & 2,5 & 0,10 & 10,00 & 0,29 & 0,01 & 0,02 & 0,14 \\
\hline Chrysophyllum marginatum & 2,5 & 0,10 & 10,00 & 0,29 & 0,01 & 0,01 & 0,14 \\
\hline
\end{tabular}


Somando-se somente as dez espécies de maior VI, obtém-se $43,19 \%$ dos valores de importância. Isso significa que quase metade do total de importância das espécies arbóreas em termos de densidade, frequência e dominância na floresta estão concentradas em poucas espécies. Este grupo de espécies é importante para a restauração ecológica, uma vez que possuem participação relevante na estrutura da floresta, definindo, por meio de seus troncos e copas, a maior parte do espaço tridimensional, onde outras formas de vida podem ocorrer. Assim, essas dez espécies de maior VI - Psychotria vellosiana, Alsophila setosa, Guatteria australis, Myrsine umbellata, Ocotea odorifera, Myrcia splendens, Casearia obliqua, Cryptocarya aschersoniana, Cryptocarya moschata e Mollinedia triflora - por sua considerável representatividade na área, podem ser consideradas como indispensáveis para recuperar áreas degradadas em florestas ciliares na região. As demais espécies são importantes para elevar a riqueza do plantio visando à recuperação, no entanto, as espécies de maior VI devem ser priorizadas para serem plantadas em maior abundância.

Considerando-se o grupo sucessional dessas, Psychotria vellosiana, Myrsine umbellata, Myrcia splendens, Cryptocarya aschersoniana e Cryptocarya moschata são espécies clímax exigentes de luz e poderiam ser plantadas primeiramente em uma área degradada, junto às espécies pioneiras citadas na Tabela 1. Após o fechamento do dossel da área, poderiam ser introduzidas Alsophila setosa, Guatteria australis, Ocotea odorifera, Casearia obliqua e Mollinedia triflora, espécies clímax tolerantes à sombra.

\section{CONCLUSÕES}

Os resultados permitem concluir que o fragmento estudado apresenta um perfil florístico caracterizado pela mistura de elementos pertencentes tanto a fitofisionomia de Floresta Ombrófila Mista quanto a Floresta Ombrófila Densa.

Dentre as espécies encontradas, recomenda-se o uso de Psychotria vellosiana, Alsophila setosa, Guatteria australis, Myrsine umbellata, Ocotea odorifera, Myrcia splendens, Casearia obliqua, Cryptocarya aschersoniana, Cryptocarya moschata e Mollinedia triflora, por sua considerável representatividade na área, podendo ser consideradas indispensáveis para a restauração de áreas degradadas em florestas ciliares na região.

\section{AGRADECIMENTOS}

A FAPESC, pela concessão de Bolsa de Iniciação Científica aos alunos que auxiliaram no desenvolvimento deste trabalho. Ao pesquisador Dr. Marcos Sobral, pela identificação das espécies da família Myrtaceae.

\section{REFERÊNCIAS BIBLIOGRÁFICAS}

ANGIOSPERM PHYLOGENY GROUP. An update of the Angiosperm Phylogeny Group classification for the orders and families of flowering plants: APG III. Botanical Journal of the Linnean Society, London, v. 161, n. 2, p. 105-121, 2009.

BERTONI, J. E. A.; MARTINS, F. R. Composição florística de uma floresta ripária na reserva estadual de Porto Ferreira, SP. Acta Botanica Brasilica, Feira de Santana, v. 1, n. 1, p. 17-26, jan. 1987.

CARVALHO, P. E. R. Técnicas de recuperação e manejo de áreas degradadas. In: GALVÃO, A. P. $M$. Reflorestamento de propriedades rurais para fins produtivos e ambientais: um guia para ações municipais e regionais. Brasília: Embrapa Florestas, 2000. cap.14, p.251-268.

CARVALHO, A. R. Fitossociologia e modelo de distribuição de espécies em área de Floresta Ombrófila Densa degradada por mineração, Joinville/SC. Revista Saúde e Ambiente/Health and Environment Journal, Joinville, v. 4, n. 1, jun. p. 42-51. 2003.

CHECCHIA, T. Avaliação de perda de solo por erosão hídrica e estudo de emergia na bacia do Rio Caeté, Alfredo Wagner - Santa Catarina. 2005. 153 f. Dissertação (Mestrado em Engenharia Ambiental) - Universidade Federal de Santa Catarina, Florianópolis, 2005.

COLONETTI, S. et al. Florística e estrutura fitossociológica em Floresta Ombrófila Denta Submontana na barragem do rio São Bento, Siderópolis, Estado de Santa Catarina. Acta Scientiarum. Biological Sciences, Maringá, v. 31, n. 4, p. 397-405, out./dez. 2009.

DEFESA CIVIL DO ESTADO DE SANTA CATARINA. Situação por município e das rodovias. Disponível em: $<\mathrm{http}: / / \mathrm{www}$.defesacivil. sc.gov.br/index.php?option $=$ com_content\&task $=$ vi ew\&id=507\&Itemid=262> Acesso em: 25 de junho de 2012.

DELITTI, W. B. C. Ciclagem de nutrientes minerais em matas ciliares. In: SIMPÓSIO SOBRE MATA CILIAR, 1., 1989, São Paulo. Anais... São Paulo: 
Fundação Cargill, 1989, p. 88-98.

ESKUCHE, U. El bosque de Araucaria con Podocarpus y los campos de Bom Jardim da Serra, Santa Catarina (Brasil meridional). Boletín de la Sociedad Argentina de Botánica, Córdoba, v. 42, n. 3-4, p. 295-308, jul./dez. 2007.

FALKENBERG, D. Matinhas nebulares e vegetação rupícola dos Aparados da Serra Geral (SC/RS), sul do Brasil. 2003. 558 f. Tese (Doutorado em Biologia Vegetal) - Universidade Estadual de Campinas, Campinas, 2003.

FLOSS, P. A. Aspectos ecológicos e fitossociológicos no entorno de nascentes em formações florestais do oeste de Santa Catarina. 2011. 154 f. Tese (Doutorado em Engenharia Florestal) - Universidade Federal de Santa Maria, Santa Maria, 2011.

FORMENTO, S. et al. Dinâmica estrutural arbórea de uma Floresta Ombrófila Mista em Campo Belo do Sul, SC. Cerne, Lavras, v. 10, n. 2, p. 196-212, jul./dez. 2004.

HELTSHE, J. F.; FORRESTER, N. E. Estimating species richness using the jackknife procedure. Biometrics, New York, v. 39, p. 1-12, 1983.

HERRERA, H. A. R. et al. Análise florística e fitossociológica do componente arbóreo da Floresta Ombrófila Mista presente na Reserva Florestal EMBRAPA/EPAGRI, Caçador, SC - Brasil. Floresta, Curitiba, v. 39, n. 3, p. 485-500, jul./set. 2009.

HIGUCHI, P. et al. Influência de variáveis ambientais sobre o padrão estrutural e florístico do componente arbóreo, em um fragmento de Floresta Ombrófila Mista Montana em Lages, SC. Ciência Florestal, Santa Maria, v. 22, n. 1, p. 79-90, jan./ mar. 2012.

HIGUCHI, P. et al. Florística e estrutura do componente arbóreo e análise ambiental de um fragmento de Floresta Ombrófila Mista Alto-montana no município de Painel, SC. Ciência Florestal, Santa Maria, v. 23, n. 1, p. 153-164, jan./ mar. 2013.

IBGE. Manual técnico da vegetação brasileira. Rio de Janeiro: Fundação Instituto Brasileiro de Geografia e Estatística, 1992. 92 p. (Série: Manuais técnicos em geociências n.1).

IZA, O. B. Parâmetros de autoecologia de uma comunidade arbórea de Floresta Ombrófila Densa, no Parque Botânico do Morro do Baú, Ilhota, SC. 2002. 50 f. Dissertação (Mestrado em Biologia Vegetal), Universidade Federal de Santa Catarina, Florianópolis, 2002.

JOLY, C. A. et al. Projeto Jacaré-Pepira - o desenvolvimento de um modelo de recomposição da mata ciliar com base na florística regional. In: RODRIGUES, R. R.; LEITÃO FILHO, H. F. Matas ciliares: conservação e recuperação. São Paulo: Editora da Universidade de São Paulo (FAPESP), 2000. p. 271-287.

KAGEYAMA, P.; GANDARA, F. B. Recuperação de áreas ciliares. In: RODRIGUES, R. R.; LEITÃO FILHO, H. F. Matas ciliares: conservação e recuperação. São Paulo: Editora da Universidade de São Paulo (FAPESP), 2000. p. 249-269.

KLAUBERG, C. et al. Florística e estrutura de um fragmento de Floresta Ombrófila Mista no Planalto Catarinense. Biotemas, Florianópolis, v. 23, n.1, p. 35-47, mar. 2010.

LIMA, W. P. Função hidrológica da mata ciliar. In: SIMPÓSIO SOBRE MATA CILIAR, 1., 1989, São Paulo. Anais... São Paulo: Fundação Cargill, 1989, p. 25-42.

LINGNER, D. et al. Caracterização da estrutura e da dinâmica de um remanescente de Floresta com Araucária no Planalto Catarinense. Pesquisa Florestal Brasileira, Colombo, v. 55, n. 2, p. 5566, jul./dez. 2007.

MANTOVANI, M. et al. Diversidade de espécies e estrutura sucessional de uma formação secundária da Floresta Ombrófila Densa. Scientia forestalis, Piracicaba, v. 67, n. 2, p. 14-26, abr. 2005.

MARTINS-RAMOS, D. et al. Florística de Floresta Ombrófila Mista Altomontana e de Campos em Urupema, Santa Catarina, Brasil. Revista Brasileira de Biociências, Porto Alegre, v. 9, n. 2, p. 156-166, abr./jun. 2011.

MULLER-DOMBOIS, D.; ELLENBERG, H. Aims and of vegetation ecology. New York: John Wiley \& Sons, 1974. $547 \mathrm{p}$.

NASCIMENTO, A. R. T. et al. Estrutura e classificação de um remanescente de floresta ripária no município de Lages, SC. Ciência Florestal, Santa Maria, v. 21, n. 2, p. 209-218, abr.jjun. 2011.

NEGRELLE, R. Composição florística e estrutura vertical de um trecho de Floresta Ombrófila Densa de Planície Quaternária. Hoehnea, São Paulo, v. 33, n. 3, p. 261-289, jul./set. 2006.

NEGRELLE, R.; SILVA, F. Fitossociologia de um trecho de floresta com Araucaria angustifolia (Bert.) O. Ktze. no município de Caçador-SC. Boletim de Pesquisa Florestal, Colombo, v. 24-25, n. 1, p. 37-54, jan./dez. 1992.

OKSANEN, J. et al. Vegan: community ecology package. R package version, v.1, p. 8-8. 2009. 
PREFEITURA MUNICIPAL DE ALFREDO WAGNER, Disponível em: < (http://ciram.epagri. rct-c.br:8080/ciram/clientes/pref_alfredo_wagner/ caracteristicas.htm) $>$ Acesso em: 10 de outubro de 2010.

R DEVELOPMENT CORE TEAM. R: A language and environment for statistical computing. R Foundation for Statistical Computing, 2008. Disponível em: <(http://www.R-project.org) $>$ Acesso em: 18 de fevereiro de 2011.

RODRIGUES, R. R.; LEITÃO FILHO, H. F. Matas Ciliares: conservação e recuperação. São Paulo: Ed. da Universidade de São Paulo - FAPESP, 2000. $320 \mathrm{p}$.

SCARIOT, E. C. Caracterização ambiental de uma fazenda produtora de madeira em Rio Negrinho, SC: subsídios para a restauração ambiental. 2008. 103 f. Dissertação (Mestrado em Recursos Genéticos Vegetais) - Universidade Federal de Santa Catarina, Florianópolis, 2008.

SILVA, R. T. Florística e estrutura da sinúsia arbórea de um fragmento urbano de Floresta Ombrófila Densa do Município de Criciúma,
Santa Catarina. 2006. 61 f. Dissertação (Mestrado em Ciências Ambientais) - Universidade do Extremo Sul Catarinense, Criciúma, 2006.

SILVA, J. A. et al. Phytosociological survey in Brazilian florest genetic reserve of Caçador. Plant Ecology, Dordrecht, v. 133, p. 1-11, 1997.

SILVA, A. C. et al. Comparação florística de florestas inundáveis das regiões Sudeste e Sul do Brasil. Revista Brasileira de Botânica, São Paulo, v. 30, n. 2, p. 257-269, abr./jun. 2007.

SILVA, A. C. et al. Relações florísticas e fitossociologia de uma Floresta Ombrófila Mista Montana secundária em Lages, Santa Catarina. Ciência Florestal, Santa Maria, v. 22, n. 1, p. 193206, jan./mar. 2012.

SWAINE, M. D.; WHITMORE, T. C. On the definition of ecological species groups in tropical rain forestas. Vegetatio, Dordrecht, v. 75, n. 1-2, p. 81-86, 1988.

TRES, D. R.; REIS, A. Técnicas nucleadoras na restauração de floresta ribeirinha em área de Floresta Ombrófila Mista, Sul do Brasil. Biotemas, Florianópolis, v. 22, n. 4, p. 59-71, out./dez. 2009. 